\section{INFLUENCE OF SENSE OF COHERENCE ON DEPRESSION AND PERCEIVED STRESS IN OLD AGE}

KEY WORDS: Sense of

Coherence; Depression;

Perceived Stress; Old Age; Old Age Homes

\section{Srinidhi C.V*}

\section{Inthumathi S.R}

\section{A. G.Shanthi}

\section{Smitha}

\section{Ruckmani}

M.Phil. Clinical Psychology (Final Year) Institute of Mental Health, Chennai, India. *Corresponding Author

M.Phil. Clinical Psychology (Final Year) Institute of Mental Health, Chennai, India.

Assistant Professor, Institute of Mental Health Chennai, India.

Associate Professor, Institute of Mental Health, Chennai, India.

Background: Old age is commonly viewed as a period of decreased physical activity, agitation and, increased calmness; depression or stress is not commonly acknowledged in the population. According to Erik Erikson, older adults experience Ego Integrity vs Despair, where people review their life cycle and accept it as something that had to be, resulting in wholeness or a sense of coherence. A lack of it would result in despair, where one's life is seen as being unproductive and guilt about the past, having not accomplished life goal leads to dissatisfaction and depression. Therefore, people with a poor sense of coherence could have higher levels of perceived stress and depression in them when compared to those who have a strong sense of coherence. Purpose: The study thus focuses on exploring the relationship between depression, perceived stress, and sense of coherence among the elderly population. Methods: Data was collected through the Sense of Coherence Scale, Perceived stress scale, and geriatric depression scale- 15 from a sample of 40 from old age (people over 60 years). Out of which 20 were living in old age homes and 20 with their families. Statistical analyses were conducted using Pearson's Coefficient of Correlation and T-test. Results: There was a mild to moderate negative correlation between perceived stress and sense of coherence and a mild to moderate negative correlation between depression and sense of coherence. There was a significant difference in the levels of perceived stress and depression between people living in their homes and old age homes.

\section{INTRODUCTION}

With increasing technology, medical care and treatment of illnesses have increased life expectancy, and consequently the population of people living up to old age. According to the UN Department of Economics and social affairs, 1 in 60 people are of the elderly population and by the year 2050, 1 in 5 people will be over 60 . This throws light onto the importance of attending to the old population- now more than ever.

Old age is a period of reduction in physical activity level owing to a decrease in muscle strength (Milanovic et al., 2013). Other than physical deterioration, cognitive decline is also present observed, subjectively by the individual (Molinuevo et al., 2017) and objectively through tests including attention, memory, processing speed, and executive abilities (Harada, Natelson Love, \& Triebel, 2013). Apart from these negative aspects, the positive features are that Old age is also associated with the time where people revisit their old friends, renew their past hobbies, spend more time with their family, and in their faith (Lillyman \& Ghaye, 2016). It is also associated, with serenity and wisdom, a wellknown stereotype.

While old age is commonly viewed as a period of decreased physical activity, agitation, and increased calmness; depression, or stress is not commonly acknowledged in the population. Depression in old age could be caused by a variety of reasons including feelings of loneliness, increased dependency both financially and physically (Dunkle et al, 2001).

Social withdrawal is a characteristic of both old age and depression which is often left unnoticed (Borson et al, 2001). Depression in old age is expressed primarily through feelings loss of interest in activities, feelings of boredom, lack of energy, helplessness, and worthlessness (Yesavage \& Brink, 1986). Stress in older adults is caused due to diminishing psychosocial resources and is found to be related to the levels of depression in older adults. Continuing threats such as chronic stressors are more likely to influence depressivesymptoms than life events such as changes in sleep, changes in eating (Jeon \& Dunkle, 2009). Ongoing daily hassles such as worries about health, not enough energy, falling, or taking medication (Dunkle et al. 2001) are ongoing persistent annoyances that could have cumulative effects leading to an increase in depressive symptoms.

The concept of 'Sense of coherence' (SOC) is attributed to Antonovsky (1993), who proposed that highly coherent individuals are better able to comprehend and manage life events in a meaningful way. SOC is built upon three components that are dynamically interconnected: comprehensibility, manageability, and meaningfulness. Comprehensibility refers to the extent to which a person perceives that the world makes sense and is structured, consistent, and predictable. Manageability refers to the degree to which a person has sufficient resources at their disposal to meet both external demands and internal needs.

Finally, meaningfulness refers to the degree to which a person feels that life is a challenging but worthy emotional engagement (Holmefur, Sundberg, Wettergren \& LangiusEklöf, 2015). Each is supposed to be essential in coping with psychosocial stressors. A person with a high sense of coherence harbors a basic trust that life, in general, is meaningful, manageable, and comprehensible.

\section{Theoretical Framework}

According to Erik Erikson, older adults experience the $8^{\text {th }}$ stage of psychosocial development, Ego Integrity Vs Despair (Papalia, Olds, \& Feldman, 2007). In this stage, people review their life cycle and accept it as something that had to be, resulting in wholeness or a sense of coherence. A lack of it would result in despair, where one's life is seen as being unproductive and guilt about the past, having not accomplished life goal leads to dissatisfaction and depression. Therefore, people with a poor sense of coherence could havehigher levels of perceived stress and depression in them when compared to those who have a strong sense of coherence. 


\section{Literature review}

Studies show that there are detrimental effects on the health of older people when the control of their activities is restricted; in contrast, interventions that enhance options for control by nursing home patients promote health. With increasing age, however, variability in preferred amounts of control also increases. Mechanisms mediating the control include health. It has negative consequences including stress, worry, at times, it has greater control over activities, circumstances, or changes in the neuroendocrine and immune systems (Rodin J, 1986). Therefore, it is important to keep in mind in the healthrelated limitations when attempting to enhance control to promote quality of life.

Quality of life was defined as a sense of well- being, meaning, and value by Sarvinmaki and Stenbock-Hult in 2000. They proposed a model that includes health, functional capacity, and coping mechanisms as intra-individual conditions for quality of life, while factors in the biophysical and sociocultural environment are described as external conditions (Sarvimäki\& Stenbock-Hult, 2000). Thus, the quality of life and in turn the stress is influenced by a multiplicity of factors. Among these, Low sense of coherence (SOC) was found to underlie the association between hostility and health problems. While hostility was associated with increased risk of health problems, when incorporating SOC into the model, it was found to better mediate the relationship (Kivimäki et al., 2002; Silarova, Nagyova, Rosenberger, van Dijk, \& Reijneveld, 2016).

Jeon and Dunkle studied the trajectories of depression and its associated factors such as types of stress and psychosocial resources among the oldest-old. The likelihood ofdepression increased with age. However, resources like mastery, social support was found to decrease this probability (Jeon\& Dunkle, 2009).

Personality factors were found to be at least partially related to both SOC and depression. In particular, low levels of neuroticism, sensation seeking, and hostility, along with higher extraversion and activity, were all significantly associated with SOC. On the other hand, lower sensation seeking, extraversion and activity, and higher levels of aggression and neuroticism, were associated with higher depression scores, either directly or indirectly through SOC (Kövi et al.,2017). This also suggests that personality could be a variable influencing Sense of Coherence.

Life satisfaction shows a pattern of decline as nutritional and mental health status decrease. Both depression and under- nutrition had a significant association with life satisfaction. The pathway by which nutrition affects life satisfaction is influenced by depression as a mediator. Moreover, nutritional status explained a small portion of the relationship between depression and life satisfaction (Ghimire, Baral, Karmacharya, Callahan, \& Mishra, 2018).

\section{Need and Rationale of the Study:}

Review of Literature indicates that depression and the perception of stress in old age have been influenced by a variety of factors. The Sense of coherence has been studied in relation to hostility and other factors predominantly. The influence of sense of coherence on stress perception and depression remains relatively unexplored, especially in Old age.The study thus focuses on exploring this relationship.

\section{METHOD}

Research design. The correlational research design was adopted for the study

Aim. The study aims to find out the relationship between sense of coherence, depression and perceived stress among the old age population living at home and old age homes.

\section{Objective.}

- To find out the relationship between Sense of Coherence and Depression.

- To find out the relationship between Sense of Coherence and Perceived Stress.

- To find out the difference between levels of Sense of Coherence, Perceived Stress and Depression in People in Old age living at home and in old age homes

\section{Hypothesis.}

- There will be no significant relationship between the Sense of Coherence and Depression.

- There will be no significant relationship between Sense of Coherence and Perceived Stress.

- There will be no significant difference between levels of Sense of Coherence, Perceived Stress and Depression in People in Old age living at home and in old age homes

\section{Sample Characteristics.}

The socio-demographic details of the participants are presented in Table 1. Participants were old age people between ages 60 years to 85 years. The average age was 69 years. A total of 40 participants were included in the study. 20 were from old age homes and care centers while 20 were living at homes. Out of the 40,30 were females and 10 were males. The participants were varying in the education level and marital status.

Table 1 Socio-demographic details of the participants

\begin{tabular}{|c|c|c|c|c|c|c|c|c|c|c|c|c|c|}
\hline & \multicolumn{2}{|c|}{ Gender } & \multicolumn{5}{|c|}{ Education } & \multicolumn{4}{|c|}{ Marital Status } & \multicolumn{2}{|c|}{ Residence } \\
\hline & Male & Female & Illiterate & $5^{\text {th }}-9^{\text {th }}$ & $10-12^{\text {th }}$ & UG & PG & Married & Widowed & Divorced & Single & Home & \begin{tabular}{|c|} 
Old \\
age homes \\
\end{tabular} \\
\hline $\begin{array}{l}\text { Number of } \\
\text { Participants }\end{array}$ & 30 & 10 & 8 & 12 & 11 & 8 & 1 & 16 & 17 & 2 & 5 & 20 & 20 \\
\hline
\end{tabular}

Sample selection. The sampling method used to select the sample was purposive sampling.

\section{Inclusion criteria.}

- Elderly people between the age of 60 to 80

- Elderly people who are willing to participate and those who signed the informed consent

\section{Exclusion criteria.}

- Elderly people with other psychiatric illnesses or with comorbid illnesses

\section{Tools used.}

1. Informed consent form. An informed consent sheet providing the aim of the study, possible effects, withdrawal of consent and the researchers' information was given, after reading which, the participants were asked to sign.

2. Socio-demographic information such as age, education, marital status, place of residence, socioeconomic status was obtained.

3. Sense of coherence scale. The SOC scale was developed by Antonovsky to measure the concept of sense of coherence. The short form of the Sense of coherence scale consists of three domains that includes comprehensibility (5 items), manageability (4 items), and meaningfulness (4 items). The respondents indicate agreement or disagreement on a 7-category semantic differential scale with two anchoring responses tailored to the content of each item. Five items $(1,2,3,5$, and 7$)$ are reversed before summing the total score. The total score can range from 13 to 91 , and a higher score indicates higher SOC. 
4. Perceived stress scale. It is a measure of the degree to which situations in one's life are appraised as stressful. It was developed by Cohen, S., Kamarck, T., and Mermelstein, R (1983). 7 out of the 14 items of PSS-14 are considerednegative $(1,2,3,8,11,12,14)$ representing perceived helplessness and the rest seven items as positive $(4,5,6,7,9,10,13)$, representing self-efficacy. Each item was rated on a five-point Likert-type scale $(0=$ never to $4=$ very often). Total scores are calculated after reversing positive items scores and then summing up all scores. Total scores range from 0 to 56 . A higher score indicates greater stress. The Cronbach's alpha values of the full scales were similar (0.82) for PSS-14 and PSS-10. The PSS 14 was administered in the study.

5. Geriatric depression scale: Geriatric Depression Scale (GDS), developed by Yesavage, et al., and used with the older population. The Geriatric depression scale Long Form consist of 30-items in which subjects are asked to answer by marking yes or no with respect to how they felt over the past week. A Short Form of Geriatric Depression Scale consists of 15 items and was developed in 1986. Out of the 15 items, 10 items indicated depression when answered positively, while the rest (item number 1,5, 1, 11, 13) indicated depression when answered negatively. Scores of 0 to 4 are considered normal, 5 to 8 indicate mild depression; 9 to 11 indicate moderate depression, and 12 to 15 indicate severe depression. The Geriatric Depression Scale can be used with older adults who are healthy, medically ill, and mild to moderately cognitively impaired. The GDS was found to have $92 \%$ sensitivity and $89 \%$ specificity when evaluated against diagnostic criteria. The scale has good reliability and validity and supported by both research and clinical practice. In a validation study comparing the Long and Short Forms of the GDS for self-rating of symptoms of depression, both were successful in differentiating depressed from nondepressedadults with a high correlation $(\mathrm{r}=0.84, \mathrm{p}<$ .001 ) (Sheikh \&Yesavage, 1986).

\section{Procedure.}

The Purpose of the study was explained. Informed consent was received from the people who volunteered to take part in the study. After this, demographic details were collected.SOC and then GDS-15 and finally PSS-14 were administered to them. The data obtained were entered into a passwordprotected laptop for further analysis.

\section{Data Analysis.}

Descriptive statistics including mean and standard deviation were obtained. Pearson's coefficient of correlation was obtained between the three variables and between the 2 groups. T-Test for independent samples was used to compare the scores of the old aged people at home and in old age homes in the three scales

\section{Ethical considerations.}

Ethical Procedure. The study followed the APA format of ethical consideration.

Risks Involved. The participants were informed of the possible risk of emotional disturbances during or post the participation in the study.

Sharing of results. The results of the study were shared with the participants upon request.

\section{Harming. No participant was harmed during this study.}

\section{RESULTS AND DISCUSSION}

This section contains the important tables and significant results that were obtained after the analysis of the data. There is also a discussion that attempts to explain and justify the results that have been obtained.
Table 2. Descriptive statistics of the two groups across the variables and Independent Sample T-test for various variables between People living in their homes and Old Age Homes

\begin{tabular}{|l|c|c|c|c|c|c|}
\hline & \multicolumn{2}{|c|}{$\begin{array}{c}\text { Perceived } \\
\text { Stress }\end{array}$} & \multicolumn{2}{c|}{$\begin{array}{c}\text { Sense of } \\
\text { Coherence }\end{array}$} & \multicolumn{2}{c|}{ Depression } \\
\cline { 2 - 7 } & Mean & $\begin{array}{l}\text { Standard } \\
\text { Deviation }\end{array}$ & Mean & $\begin{array}{l}\text { Standard } \\
\text { Deviation }\end{array}$ & Mean & $\begin{array}{l}\text { Standard } \\
\text { Deviation }\end{array}$ \\
\hline $\begin{array}{l}\text { Old age } \\
\text { home }\end{array}$ & 37.25 & 3.71 & 47.2 & 6.69 & 3.05 & 1.82 \\
\hline Home & 31.7 & 8.11 & 50.3 & 7.46 & 5 & 3.94 \\
\hline Total & 34.47 & 6.83 & 48.75 & 7.17 & 4.025 & 3.19 \\
\hline $\begin{array}{l}\text { P-value } \\
\text { of T-test }\end{array}$ & \multicolumn{2}{|c|}{$.008^{* *}$} & \multicolumn{2}{|c|}{.175} & \multicolumn{2}{|c|}{$.052^{*}$} \\
\hline
\end{tabular}

* Significant at the 0.05 level (2-tailed).

**Significant at the 0.01 level (2-tailed)

Table 2 shows the descriptive statistics for the data that were analyzed.As seen from the table a mean of 34 was obtained for perceived stress, a mean of 48 was obtained for the sense of coherence and a mean of 4 was obtained for depression. The data result is suggestive that despite having high levels of perceived stress there are comparatively low levels of depression in the sample along with average levels of Sense of Coherence.

Table 2 also shows that there is a significant difference in perceived stress between people living in their homes and people living in old age homes at 0.01 level. There is a significant difference in depression between people living in their homes and people living in old age homes at 0.05 level. The 2 null hypotheses were therefore rejected. As mentioned earlier there could be other contributing factors that could lead to the difference in stress and depression between people living in Old age homes and their houses. The Sense of coherence does not have a significant difference between people in old age homes and people in their houses suggesting, introspective understanding and integration of self happen at old age, independent of social factors and resources. The null hypothesis was accepted. However, according to Carstens and Spangenberg (1997) sense of coherence does increases with age.

This direction, differences of SOC across the lifespan could be the focus for the future researchers.

Table 3 Pearson's Correlation Coefficient between the variables $(n=40)$

\begin{tabular}{|l|c|c|}
\hline & Perceived Stress & Depression \\
\hline Sense of Coherence & $-.472^{* *}$ & $.438^{* *}$ \\
\hline \multicolumn{2}{|l|}{$* *$. Correlation is significant at the 0.01 level (2-tailed). } \\
\hline
\end{tabular}

Table 3 shows the Pearson's correlation coefficient values that were obtained between the sense of coherence and depression, sense of coherence, and perceived stress. A correlation coefficient of -4.472 which is significant at 0.01 level, and has led to the null hypothesis being rejected. It indicates there is a negative relationship between sense of coherence and perceived stress. In other words, when the sense of coherence decreases levels of perceived stress was increased. This finding is in accordance with Erickson's theory of psychosocial development (Papalia, Olds, \& Feldman, 2007). It implies that when people have a unified meaningful sense of self their levels of stress perceived is low. According to Richard Lazarus when a person evaluates the situation based on his/her capacity to handle the situation and his/her stress level varies according to it (Folkman \& Lazarus, 1988). Therefore, when a person has a clear and intelligible understanding of oneself they will have an accurate perception of their ability to handle the situation and consequently, their stress levels will be low.From table 3 we can also see that the correlation coefficient of depression and sense of coherence is 0.438 which is significant at 0.01 level. The null hypothesis was thus rejected, indicating there is a 
positive correlation between depression and sense of coherence. When the level of depression increases the sense of coherence will increase. This is contrary to Erickson's theory. Despair is a complex emotion that can be described as a combination of depression and stress together. Stress results in immediate autonomic arousal and can be clearly distinguished from a feeling of calmness or contentment. However, depression decreases the arousal state of the body and might be different to distinguish from the calm experienced upon reaching a higher sense of coherence. Depression is often associated with rumination (Papageorgiou and Wells, 2001). A poor ability to distinguish and therefore interpret one's inner emotional states could contribute to mislabeling of rumination as introspection. Another reason could be that when people are depressed, they tend to ruminate about past experiences and their actions. Although most often these ruminations are negative in content, it might inadvertently contribute to a better and deeper understanding of self.

Another important factor to be noted is that the strength of the relationship between depression and sense of coherence is at a mild to a moderate level, implying that there are other factors that contribute to a better understanding of self as well and that depression may not always lead an improved understanding of self. For e.g., Personality disposition such as low levels of neuroticism and high levels of extroversion was found to influence SOC (Kövi et al., 2017).

Table 4 Pearson's Correlation Coefficient between the variables for People living in Old Age Homes and People living in their Homes

\begin{tabular}{|c|c|c|c|c|}
\hline & \multicolumn{2}{|c|}{ Perceived Stress } & \multicolumn{2}{|c|}{ Depression } \\
\hline & $\begin{array}{l}\text { Old Age } \\
\text { Homes }\end{array}$ & Homes & $\begin{array}{l}\text { Old Age } \\
\text { Homes }\end{array}$ & Homes \\
\hline $\begin{array}{l}\text { Sense of } \\
\text { Coherence }\end{array}$ & -.220 & $-.543^{*}$ & .206 & $.505^{*}$ \\
\hline
\end{tabular}

* Significant at the 0.05 level

From Table 4 we can see that there is a stronger correlation between sense of coherence and depression, sense of coherence, and perceived stress among people living in their homes compared to the people living in the old age homes. This could be because the people living in an old age home there are other contributory factors that influence depression and stress. Old age homes have scheduled activities and group therapy sessions among the residents this could facilitate the development of better coping strategies that could reduce depression and stress irrespective of their sense of coherence. However, at home, these facilitating events might be absent causing greater influence of sense of coherence on Stress and Depression. The various factors that led to the result need to be explored. Behavioral activities that facilitate in the reduction of stress and depression can be practiced at home to help foster better mental health.

\section{Summary}

Old age is commonly viewed as a period of decreased physical activity, agitation, and increased calmness; depression or stress is not commonly acknowledged in the population. Social withdrawal is a characteristic of both old age and depression which is often left unnoticed. According to Erik Erikson, older adults experience Ego Integrity vs Despair, where people review their life cycle and accept it as something that had to be, resulting in wholeness or a sense of coherence. A lack of it would result in despair, where one's life is seen as being unproductive and guilt about the past, having not accomplished life goal leads to dissatisfaction and depression. The study thus focused on exploring the relationship between depression, perceived stress, and sense of coherence among the elderly population. Data was collected through the Sense of Coherence Scale, Perceived stress scale, and geriatric depression scale- 15 from a sample of 40 from old age (people over 60 years). Out of which 20 were living in old age homes and 20 with their families. Statistical analyses were conducted using Pearson's Coefficient of Correlation and T-test. Results showed that people with a stronger sense of coherence have lower levels of perceived stress and higher levels of depression in them when compared to those who have a lower sense of coherence. There is a significant difference in perceived stress and depression between people in old age homes and people living in their homes as well.

\section{CONCLUSION:}

The results of the study showed that there is a negative relationship between sense of coherence and perceived stress. In other words, when the sense of coherence decreases levels of perceived stress is increased. There is a positive relationship between sense of coherence and depression i.e., when the sense of coherence increases levels of depression is increased.

There is a stronger correlation between sense of coherence and depression, sense of coherence, and perceived stress among people living in their homes compared to the people living in the old age homes. There is a significant difference in perceived stress and depression between people living in their homes and people living in old age homes. There is no significant difference in sense of coherence between people living in their homes and people living in old age homes.

\section{Limitations and Implications:}

Limitations of the study include the small sample as a result of which results of the study cannot be generalized. The sample consists of a greater number of females and may have not been representative of the entire population. The study sample was collected from one particular old age home and could have skewed the results as well. For further studies, a greater sample size across various old age homes factoring in the various behavioral activities and psychological influences must be assessed to help understand the other possible influences on depression and perceived stress in the elderly population.

\section{REFERENCES}

1. Andreou, E., Alexopoulos, E. C., Lionis, C., Varvogli, L., Gnardellis, C., Chrousos, G. P., \& Darviri, C. (2011). Perceived Stress Scale: Reliability and Validity Study in Greece, International Journal of Environmental Research and Public Health, 8,3287-3298. doi: 10.3390/ijerph8083287

2. Borson, S., Bartels, S., Colenda, C., Gottlieb, G., \& Meyers, B. (2001). Geriatric Mental Health Services Research: Strategic Plan for an Aging Population. American Journal of Geriatric Psychiatry, 9, 191-204.

3. Carstens, J. A., \& Spangenberg, J. J. (1997). Major Depression: A Breakdown in Sense of Coherence? Psychological Reports, 80(3_suppl), 1211-1220. https://doi.org/10.2466/pr0.1997.80.3c.1211

4. Dunkle, R., Roberts, B., \& Haug, M. The Oldest-Old in Everyday Life: Self Perception, CopingWith Change, and Stress.NewYork:Springer;2001.

5. Folkman, S., \& Lazarus, R. S. (1988). The relationship between coping and emotion: Implications for theory and research. Social Science and Medicine, 26(3),309-317.https://doi.org/10.1016/0277-9536(88)90395-4

6. Ghimire, S., Baral, B. K., Karmacharya, I., Callahan, K., \& Mishra, S. R. (2018). Life satisfaction among elderly patients in Nepal: associations with nutritional and mental well-being. Health and Quality of Life Outcomes, 16(1), 118. https://doi.org/10.1186/s12955-018-0947-2

7. Greenberg, S. A. (2019). The Geriatric Depression Scale (GDS). Retrieved from https://web.stanford.edu/ yesavage/GDS.html

8. Harada, C. N., Natelson Love, M. C., \& Triebel, K. L. (2013). Normal cognitive aging.

9. Clinics in Geriatric Medicine, 29(4), 737-752. https://doi.org/10.1016/j.cger. 2013.07.002

10. Holmefur, M., Sundberg, K., Wettergren, L., \& Langius-Eklöf, A. (2015). Measurement properties of the 13-item sense of coherence scale using Rasch analysis. Quality of Life Research, 24(6), 1455-1463. https://doi.org/10.1007/ s11136-014-0866-6

11. Jeon, H.-S., \& Dunkle, R. E. (2009). Stress and Depression Among the OldestOld: A Longitudinal Analysis. Research on Aging, 31(6), 661-687. https://doi.org/10.1177/0164027509343541

12. Kivimäki, M., Elovainio, M., Vahtera, J., Nurmi, J. E., Feldt, T., KeltikangasJärvinen, L., \& Pentti, J. (2002). Sense of coherence as a mediator between hostility and health seven- year prospective study on female employees. Journal of Psychosomatic Research, 52(4), 239-247. https://doi.org/10.1016/ S0022-3999(01)00305-1

13. Kövi, Z., Odler, V., Gacsályi, S., Hittner, J. B., Hevesi, K., Hübner, A., \& Aluja, A. (2017). Sense of coherence as a mediator between personality and depression. Personality and Individual Differences, 114, 119-124. https:// doi.org/10.1016/j.paid.2017.03.064 
14. Lillyman, S., \& Ghaye, T. (2016). Preliminary results of an international study exploring and comparing positive aspects and concerns of growing older in different societies. The Journal of the Institute of Ageing and Health (West Midlands), 9, 22-26.

15. Milanovic, Z., Pantelic, S., Trajkovic, N., Sporiš, G., Kostic, R., \& James, N. (2013). Age- related decrease in physical activity and functional fitness among elderly men and women. Clinical Interventions in Aging, 8, 549-556. https://doi.org/10.2147/CIA.S44112

16. Molinuevo,J.L., Rabin, L. A., Amariglio, R., Buckley, R., Dubois, B., Ellis, K. A., ,. Subjective Cognitive Decline Initiative (SCD-I) Working Group. (2017).

17. Implementation of subjective cognitive decline criteria in research studies. Alzheimer's \& Dementia: The Journal of the Alzheimer's Association, 13(3), 296-311.https://doi.org/10.1016/j.jalz.2016.09.012

18. Papalia, D. E., Olds, S. W., \& Feldman, R. D. (2007). Human development.McGraw-Hill. Rodin J. (1986). Aging and Health :Effects of the sense of control.Science,233(4770),1271-1276.

19. Sarvimäki, A., \& Stenbock-Hult, B. (2000). Quality of life in old age described as a sense of well-being, meaning and value. Journal of Advanced Nursing, 32(4), 1025-1033.https://doi.org/10.1046/j.1365-2648.2000.01568.x

20. Silarova, B., Nagyova, I., Rosenberger, J., van Dijk, J. P., \& Reijneveld, S. A. (2016). Sense of coherence as a mediator between hostility and healthrelated quality of life among coronary heart disease patients. Heart and Lung: Journal of Acute and Critical Care, 45(2), 126-131. https://doi.org/10.1016/j. hrtlng.2015.11.004

21. Yesavage, J. A., \& Brink, T. L. (1986). National-Security Strategy - Choices and Limits - Cimbala,sj. Am. Polit. Sci. Rev., 80(1), 360-361. https://doi. org $/ 10.2307 / 1957152$ 